\title{
Anti-Lipid IgG Antibodies Are Produced via Germinal Centers in a Murine Model Resembling Human Lupus
}

\author{
Carlos Wong-Baeza ${ }^{1,2 *}$, Albany Reséndiz-Mora ${ }^{2}$, Luis Donis-Maturano', \\ Isabel Wong-Baeza ${ }^{3}$, Luz Zárate-Neira², Juan Carlos Yam-Puc ${ }^{1}$, Juana Calderón-Amador', \\ Yolanda Medina ${ }^{4}$, Carlos Wong ${ }^{2}$, Isabel Baeza ${ }^{2}$ and Leopoldo Flores-Romo ${ }^{\text {* }}$ \\ 'Department of Cell Biology, Center for Research and Advanced Studies, CINVESTAV-IPN, National Polytechnic Institute, \\ Mexico City, Mexico, ${ }^{2}$ Laboratorio de Biomembranas, Departamento de Bioquímica, Escuela Nacional de Ciencias \\ Biológicas (ENCB), IPN, Ciudad de México, México, ${ }^{3}$ Laboratorio de Inmunología Molecular II, Departamento de \\ Inmunología, ENCB, IPN, Ciudad de México, México, ${ }^{4}$ Laboratory of monoclonal antibodies, Institute of Epidemiological \\ Diagnosis and Reference, Mexico City, Mexico
}

\section{OPEN ACCESS}

Edited by: Harry W. Schroeder, University of Alabama at Birmingham, USA

Reviewed by: Paulo Vieira, Institut Pasteur de Paris, France Gregory C. Ippolito, University of Texas at Austin, USA

${ }^{*}$ Correspondence: Carlos Wong-Baeza charlywong@icloud.com; Leopoldo Flores-Romo lefloresromo@gmail.com

Specialty section: This article was submitted to B Cell Biology, a section of the journal

Frontiers in Immunology

Received: 03 May 2016 Accepted: 16 September 2016 Published: 29 September 2016

Citation: Wong-Baeza C, Reséndiz-Mora A, Donis-Maturano L, Wong-Baeza I, Zárate-Neira L, Yam-Puc JC,

Calderón-Amador J, Medina Y, Wong C, Baeza I and Flores-Romo L (2016) Anti-Lipid IgG Antibodies Are Produced via Germinal Centers in a Murine Model Resembling Human

Front. Immunol. 7:396. doi: 10.3389/fimmu.2016.00396
Anti-lipid lgG antibodies are produced in some mycobacterial infections and in certain autoimmune diseases [such as anti-phospholipid syndrome, systemic lupus erythematosus (SLE)]. However, few studies have addressed the B cell responses underlying the production of these immunoglobulins. Anti-lipid IgG antibodies are consistently found in a murine model resembling human lupus induced by chlorpromazine-stabilized nonbilayer phospholipid arrangements (NPA). NPA are transitory lipid associations found in the membranes of most cells; when NPA are stabilized they can become immunogenic and induce specific IgG antibodies, which appear to be involved in the development of the mouse model of lupus. Of note, anti-NPA antibodies are also detected in patients with SLE and leprosy. We used this model of lupus to investigate in vivo the cellular mechanisms that lead to the production of anti-lipid, class-switched IgG antibodies. In this murine lupus model, we found plasma cells (Gr1-, CD19-, CD138+) producing NPA-specific IgGs in the draining lymph nodes, the spleen, and the bone marrow. We also found a significant number of germinal center B cells (lgD-, CD19+, PNA ${ }^{+}$) specific for NPA in the draining lymph nodes and the spleen, and we identified in situ the presence of NPA in these germinal centers. By contrast, very few NPA-specific, extrafollicular reaction B cells $\left(B 220^{+}\right.$, Blimp1+) were found. Moreover, when assessing the anti-NPA IgG antibodies produced during the experimental protocol, we found that the affinity of these antibodies progressively increased over time. Altogether, our data indicate that, in this murine model resembling human lupus, B cells produce anti-NPA IgG antibodies mainly via germinal centers.

Keywords: non-bilayer phospholipid arrangements, systemic lupus erythematosus, anti-lipid IgG antibodies, antigen-specific cells, autoimmune disease

\section{INTRODUCTION}

Anti-lipid IgG antibodies are produced during malaria, mycobacterial infections, autism spectrum disorders, and some autoimmune diseases, such as the anti-phospholipid syndrome and systemic lupus erythematosus (SLE) (1-4). Likewise, anti-lipid IgGs are consistently found in a mouse model of lupus that has several of the clinical and pathological features of SLE patients, including serum 
anti-nuclear, anti-histone, anti-coagulant and anti-cardiolipin antibodies, weight loss, glomerulonephritis, anorexia, and facial lesions resembling the malar rash of lupus patients (5). This model can be triggered either by the administration of chlorpromazine (CPZ), procainamide, or hydralazine, which induce stable non-bilayer phospholipid arrangements (NPA) on cell membranes, or by administering liposomes bearing NPA (L-NPA) elicited by these same agents or by cations, such as manganese, or even by injecting a NPA-specific monoclonal antibody (H308, which stabilizes NPA on murine cells). NPA are three-dimensional structures that can emerge when anionic phospholipids with a conical shape, such as phosphatidic acid (PA), phosphatidylserine, or cardiolipin, produced an intermediate form of the tubular hexagonal phase II or inverted micelle that is inserted in a bilayer of lipids (Figure 1) (6-8). NPA are transient lipid associations found on the membrane of most cells; when they are stabilized, they can become immunogenic and induce the production of specific antibodies that participate in the pathogenesis of this mouse model of lupus $(5,9)$; moreover, anti-NPA antibodies are found in patients with SLE and leprosy $(5,10)$. On the other hand, liposomes made of a lipid extract from Mycobacterium smegmatis elicit high titers of anti-lipid IgG antibodies, which are cross-reactive with lipid antigens from Mycobacterium tuberculosis (1). However, few studies have addressed the cellular reactions that lead to the production of these anti-lipid IgG antibodies.
In adaptive antibody responses to most protein antigens, activation and proliferation of B cells occur either in secondary follicles where B cells form germinal centers, or in extrafollicular foci (11-13). Germinal center B cells (IgD-, CD19+, $\mathrm{PNA}^{+}$) switch the antibody isotype and mutate the genes that encode their antigen receptors. These processes can change the antibody affinity and even the antibody specificity. The mutated cells that produce high-affinity antibodies are selected to become either plasma cells $\left(\mathrm{Gr} 1^{-}, \mathrm{CD} 19^{-}, \mathrm{CD} 138^{+}\right)$or memory B cells, whereas cells that have lost affinity or acquired autoreactivity are typically eliminated $(14,15)$. Normally, CD $4^{+} \mathrm{T}$ (follicular) helper cells are critical for the germinal center formation and the subsequent $B$ cell selection. Both processes involve engagement of at least CD40 on B cells by CD40-ligand on T cells, although there are reports describing the generation of high-affinity $\mathrm{B}$ cells in large germinal centers in the absence of $\mathrm{T}$ cells, or in absence of signaling through CD40 or CD28. However, in these latter cases, extensive cross-linking of the $\mathrm{B}$ cell receptors, and a high frequency of antigen-specific B cells of at least 1 in 1,000, is required (16). Extrafollicular reactions are responsible for the fast production of antibodies upon antigen encounter, and the extrafollicular B cells $\left(\mathrm{B} 220^{+}\right.$, Blimp $\left.1^{+}\right)$are typically found in the medullary cords of lymph nodes and in foci in the spleen red pulp. In some circumstances, the extrafollicular responses can be associated with immunoglobulin class switching but, at the most, with only low levels of hypermutation $(11,17)$. In our
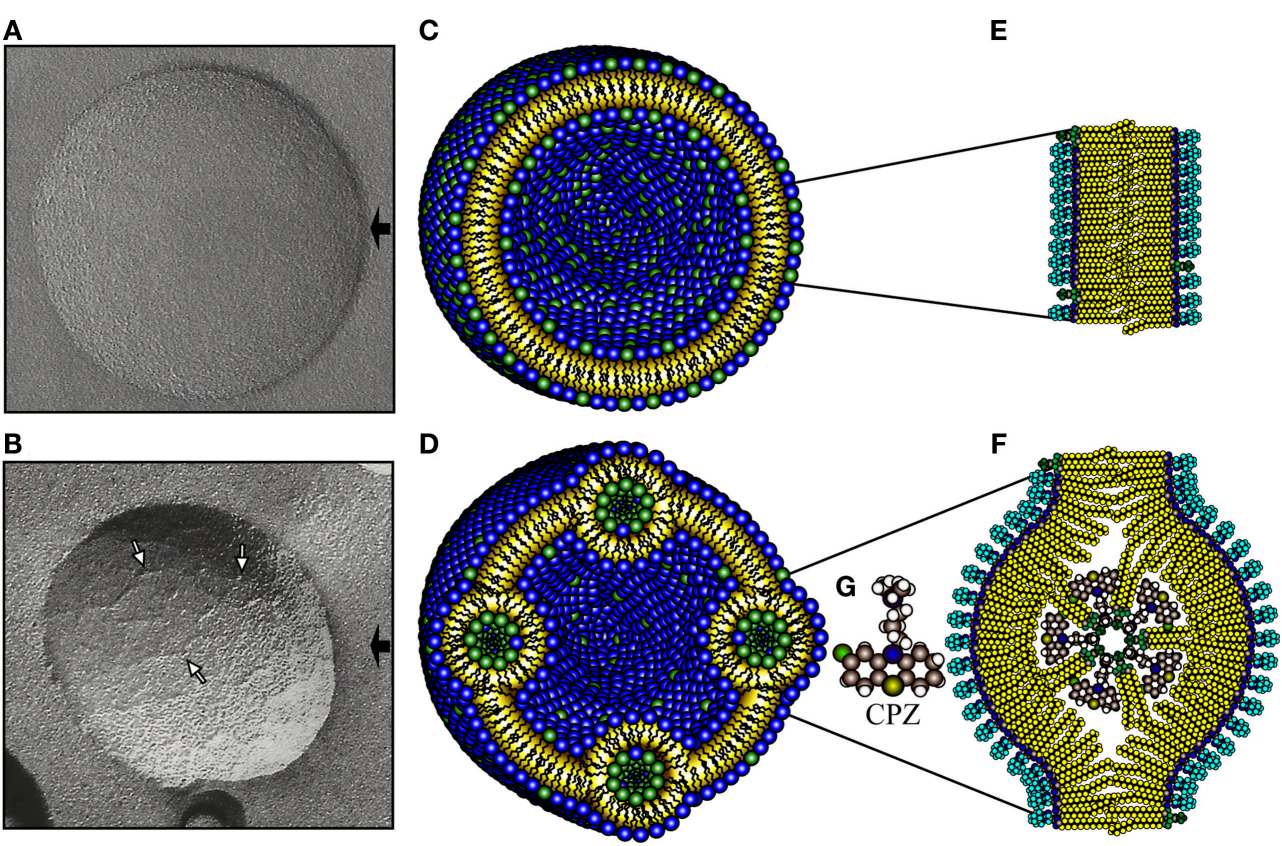

FIGURE 1 | NPA as detected by freeze-fracture electron microscopy, together with a schematic representation. Freeze-fracture electron microscopy of liposomes made of $\mathrm{L}-\alpha$-phosphatidylcholine (PC)/L- $\alpha$-phosphatidic acid (PA) (2:1 molar ratio) alone (A) or incubated with chlorpromazine (CPZ) 3 mM (B). The black arrows indicate the shadow direction and the white arrows show NPA, either isolated or forming small strings. Schematic representation illustrates the molecular organization of the phospholipids in a smooth liposome without NPA (C) or bearing NPA (D). The amplifications to the right depict the phospholipids in the bilayer arrangements (E) and in the NPA (F). The bilayers in the NPA are mainly formed by PC, whose polar regions (blue color) are exposed on the zones of the lipid bilayer where the inverted micelle is inserted. The novel exposure of these polar regions of PC induces the production of antibodies against them. The inverted micelle is mainly formed by PA (polar regions in green color) together with CPZ (9). The molecular structure of CPZ is shown in (G). 
study, we used an established murine model resembling human lupus induced by the stabilization of NPA to investigate if the cellular mechanisms that lead to the production of anti-NPA IgG antibodies are through germinal centers or through extrafollicular reactions.

\section{MATERIALS AND METHODS}

\section{Preparation and Characterization of Liposomes and Liposomes Bearing NPA}

Egg yolk L- $\alpha$-PA, egg yolk L- $\alpha$-phosphatidylcholine (PC) and CPZ were purchased from Sigma Aldrich (St. Louis, MO, USA). Liposomes were formed with the cylindrical phospholipid PC and the anionic and conical phospholipid PA in a molar ratio of 2:1. Nine micromoles of the phospholipid mixture were dissolved in $1 \mathrm{~mL}$ of diethyl ether, $330 \mu \mathrm{L}$ of TS $(10 \mathrm{mM}$ Tris- $\mathrm{HCl}$, $1 \mathrm{mM} \mathrm{NaCl}, \mathrm{pH} 7$ ) were added, and the mixture was sonicated three times (5-s sonication followed by $30 \mathrm{~s}$ resting period) in a Lab Supply G112SPI sonicator (Laboratory Supplies, Hicksville, NY, USA). The diethyl ether was then removed under a stream of oxygen-free dry nitrogen at reduced pressure, using a rotary evaporator at $37^{\circ} \mathrm{C}$. TS was added to a final volume of $1 \mathrm{~mL}$ and the liposomes were filtered through MF-Millipore membranes (Billerica, MA, USA) with $0.45 \mu \mathrm{m}$ pores. To induce the formation of NPA, liposomes in TS were incubated $30 \mathrm{~min}$ at $37^{\circ} \mathrm{C}$ in the presence of CPZ (3 mM) (18). To stain the liposomes, $100 \mu \mathrm{L}$ of the red-fluorescent PKH26 dye (Sigma Aldrich) diluted 1:500 in diluent C (Sigma Aldrich) were added to $100 \mu \mathrm{L}$ of smooth liposomes (SL) or L-NPA and incubated for $5 \mathrm{~min}$ at room temperature. To stop the staining, $200 \mu \mathrm{L}$ of phosphate buffered saline (PBS) with $1.0 \%$ bovine serum albumin (BSA) (US Biologicals, Swampscott, MA, USA) were added, and then centrifuged at $268,000 \times g$ for $15 \mathrm{~min}$ in the ultracentrifuge Optima TM MAX-XP (Beckman Coulter, Brea, CA, USA). The supernatant was discarded and the liposomes resuspended in PBS. All the final preparations of liposomes were negative for LPS contamination, as assessed by the gel clot LAL method (Charles River Endosafe, Charleston, SC, USA). The final preparations were evaluated by freeze-fracture electron microscopy, as reported before (9).

\section{Mouse Model of Lupus}

To induce the lupus-like disease in mice, we used the protocol as described before $(5,9)$. Briefly, we used three groups $(\mathrm{A}, \mathrm{B}$, and $\mathrm{C}$ ) of 6-week-old female pathogen-free BALB/c mice. Each group was divided into three subgroups of six mice each. Subgroup one received saline solution (SS), subgroup two SL and subgroup three liposomes bearing CPZ-induced NPA, on days 1 and $16(50 \mu \mathrm{L}$, intrasplenic). Before the first injection, mice received intraperitoneally $100 \mu \mathrm{L}$ of complete Freund's adjuvant (CFA, Sigma Aldrich) diluted 1:2 with TS, and before the second injection, the mice received $100 \mu \mathrm{L}$ of incomplete Freund's adjuvant (Sigma Aldrich) diluted 1:2 with TS. Additionally, on days 2, 17, and 32, $50 \mu \mathrm{L}$ of SS, SL, or liposomes bearing CPZ-induced NPA, were injected intradermally in the inguinal region of these mice, instead of the intraperitoneal region as was previously described (5). Blood was taken before and 10,20, and 35 days after the first intra-splenic injection. Sera were heated at $56^{\circ} \mathrm{C}$ for $30 \mathrm{~min}$ to inactivate complement, and then frozen in aliquots at $-70^{\circ} \mathrm{C}$. Mice of groups $\mathrm{A}, \mathrm{B}$, and C were sacrificed on days 10,20 , and 35 , respectively, after the first intra-splenic injection (Protocol illustrated in Figure S1 in Supplementary Material).

The spleens and inguinal lymph nodes (ILN) of each mouse of the A, B, or C groups were extracted, sectioned and the cell suspensions obtained were placed in fluorescence-activated cell sorting (FACS) buffer solution containing PBS with $0.1 \%$ BSA and $0.01 \%$ sodium azide (Sigma Aldrich) for flow cytometry analysis. Bone marrows were extracted and placed also in FACS buffer solution for flow cytometry studies. All our protocols for animal care and use were reviewed and approved by the Bioethics Committee of our Institution following international rules (19).

\section{Confirmation of the Development of the Lupus-Like Disease in Mice in Response to Intradermal Injection of Liposomes Bearing NPA}

A group of 10 mice was injected intradermally in the inguinal region once a week with liposomes bearing CPZ-induced NPA, and sacrificed 4 months after the first intra-splenic injection to confirm that these mice, which were injected intradermally instead of intraperitoneally, also developed the autoimmune disease resembling human lupus. Blood samples were taken every month, anti-NPA antibodies, as well as anti-histone and anticardiolipin antibodies, were measured in their sera, as reported before (5). A goat peroxidase-tagged anti-mouse antibody to IgG, $\operatorname{IgM}$, and $\operatorname{IgA}$ isotypes was used to assess total antibodies to NPA; whereas goat peroxidase-tagged anti-mouse to total IgGs (Sigma Aldrich) diluted 1:2,000 was used as a secondary antibody in the ELISA to determine NPA-specific IgG antibodies only. Where indicated, L-NPA stained with the PKH26 red-fluorescent dye were used as antigens in the ELISA, in order to verify that NPAfluorescent labeling did not modify the Ab recognition of NPAs.

\section{Identification of NPA-Specific B Cells and Plasma Cells by Flow Cytometry}

Inguinal lymph nodes, spleens, and bone marrow were macerated in glass mortars and then filtered with a $75 \mu \mathrm{m}$ cell strainer (Becton Dickinson, San Jose, CA, USA). The organs from two mice from the same subgroup were pooled together for analysis. Red blood cells from spleens were lysed and cell suspensions were resuspended in FACS buffer solution. Before staining, cells were incubated with Universal Blocking Reagent (Block Biogenex, San Ramón, CA, USA) diluted 1:10 with PBS for $10 \mathrm{~min}$ at $4^{\circ} \mathrm{C}$ and then washed. Plasma cells, germinal center, and extrafollicular $B$ cells were labeled with the corresponding set of antibodies indicated below, and with L-NPA, which were previously stained with the lipophilic red-fluorescent dye $\mathrm{PKH} 26$. This latter procedure allowed us, therefore, to analyze the populations specific for the inducing antigen (NPA).

To evaluate NPA-specific germinal center B cells, cell suspensions were labeled with anti-IgD-PerCP/Cy5.5, anti-CD19-APC 
and PNA-FITC (Vector Laboratories, Burlingame, CA, USA) and $10 \mu \mathrm{L}$ of the PKH26-stained liposomes for $30 \mathrm{~min}$ at $4^{\circ} \mathrm{C}$ and then washed and fixed with $1 \%$ paraformaldehyde (Sigma Aldrich).

Extrafollicular B cells were labeled with anti-B220-FITC, anti-CD5-AF647, and $10 \mu \mathrm{L}$ of the PKH26-stained liposomes for $30 \mathrm{~min}$ at $4^{\circ} \mathrm{C}$ and then washed. Subsequently, $50 \mu \mathrm{L}$ of Cytofix/ Citoperm (Becton Dickinson) was added; and after $10 \mathrm{~min}$ at $4^{\circ} \mathrm{C}$, the cells were washed with PermWash buffer (Becton Dickinson) $1 \times$; an anti-Blimp1-biotinylated antibody (Abcam, Burlingame, CA, USA), followed by streptavidin coupled to Pacific Blue (Invitrogen, Carlsbad, CA, USA) diluted in $50 \mu \mathrm{L}$ of PermWash buffer, was added, and the cells were incubated for $30 \mathrm{~min}$ at $4^{\circ} \mathrm{C}$. The cells were washed a final time with PermWash buffer and fixed with $1 \%$ paraformaldehyde.

To evaluate NPA-specific plasma cells, cell suspensions were labeled first with anti-Gr1-PerCP, anti-CD19-APC, and with anti-CD138-Brilliant Violet 421 for $30 \mathrm{~min}$ at $4^{\circ} \mathrm{C}$ and then washed. Subsequently the procedure for intracellular labeling was as described: $50 \mu \mathrm{L}$ of Cytofix/Citoperm was added; and after $10 \mathrm{~min}$ at $4^{\circ} \mathrm{C}$, the cells were washed with PermWash buffer. Anti-IgG-FITC (Jackson Immunoresearch) diluted in $50 \mu \mathrm{L}$ of PermWash buffer and $10 \mu \mathrm{L}$ of the PKH26-stained liposomes were added, the cells were incubated for $30 \mathrm{~min}$ at $4^{\circ} \mathrm{C}$, washed with PermWash buffer and fixed with $1 \%$ paraformaldehyde.

The samples were acquired in a BD LSR Fortessa cytometer (Becton Dickinson) and analyzed with FlowJo 10.0.6 (Tree Star, Inc., Ashland, OR, USA). Appropriate isotype controls were included in all sets of experiments. All antibodies were from BioLegend (San Diego, CA, USA) unless otherwise indicated.

\section{In Situ Identification of NPAs in Germinal Centers by Immunofluorescence}

To identify NPAs in germinal centers, mice were sacrificed at day 35 after NPA inoculations and the ILNs were removed, embedded in Tissue-Tek (Sakura Finetek, Torrance, CA, USA), frozen, and stored at $-70^{\circ} \mathrm{C}$. Tissues were cut in $6-\mu \mathrm{m}$ sections using a cryostat (Leica 1900 CM, Wetzlar, DE), sections were mounted on poly-L-Lysine-charged slides, fixed in $2 \%$ formaldehyde (Polysciences, Warrington, PA, USA) for $1 \mathrm{~h}$ at room temperature and washed in PBS containing 0.1\% BSA. Tissue sections were treated with Universal Blocking Reagent $(1: 10)$ for $10 \mathrm{~min}$ at room temperature, and with mice sera diluted 1:10 in PBS for $10 \mathrm{~min}$ at room temperature. ILN sections were incubated overnight at $4^{\circ} \mathrm{C}$ with the following combination of antibodies: biotinylated $\mathrm{H} 308$ (NPA-specific) mouse monoclonal antibody and PNA-FITC, or with $\mathrm{H} 308$ and rat anti-IgD (Becton Dickinson) or with H308 and rat anti-B220 (Becton Dickinson). After further washes, slides were incubated $1 \mathrm{~h}$ at room temperature with anti-rat-AF488 (Thermo Fisher Scientific, Waltham, MA, USA) and washed three times. Subsequently, the slides were incubated for $15 \mathrm{~min}$ at room temperature with streptavidin-AF610 (Thermo Fisher Scientific) and washed. Finally, blue nuclear counter-staining was done using DAPI (Invitrogen) for $5 \mathrm{~min}$ at room temperature and the slides were washed. Slides were then mounted with DABCO (Sigma Aldrich) and examined with Image-Pro PLUS software in an Olympus BX51 microscope (Olympus Corporation, Hachioji, TY, JPN). Appropriate isotype controls were included in each experiment.

\section{Anti-NPA IgG Antibodies and Affinity Maturation during the Experimental Procedure}

To determine whether the IgG antibodies to NPA underwent affinity maturation during the time course of the experimental protocol, we performed antigen-specific ELISAs for the antiNPA IgG antibodies, both in the absence and in the presence of urea (Sigma Aldrich) 7M (20-22). ELISAs were performed as indicated above (5), but after adding the sera containing the anti-NPA IgG antibodies, urea 7M was added to each well for $10 \mathrm{~min}$ (secondary reagents were added after the corresponding washes). Under the astringent effects of urea, the antibodies with low affinities for antigen will detach more easily than the antibodies bound with higher affinities, and the result of this can be quantitated. Therefore, in this assay, the percentage of urea-resistant IgG anti-NPA antibodies can be calculated regarding the total IgG anti-NPA antibodies. The kinetic follow-up of this behavior during the immunization procedures will indicate whether affinity maturation of these antibodies has occurred. While low percentage indicates that most NPA-specific antibodies detached from antigen (low affinity), high percentage reveals that most antibodies remained attached to antigen despite the high-stringency urea wash (high affinity).

\section{RESULTS}

\section{Characterization of Liposomes Bearing CPZ-Induced NPA}

Freeze-fracture electron microscopy of PC/PA (2:1) liposomes revealed vesicles with smooth surfaces (Figure 1A), as previously described $(9,18)$. The addition of $3 \mathrm{mM} \mathrm{CPZ}$ induced the formation of NPA (Figure 1B), which have an average thickness of $5 \mathrm{~nm}$; these NPA are isolated or form small strings that do not modify the liposome size. PC/PA (2:1) liposomes bearing CPZ-induced NPA and stained with PKH26 dye showed an image similar to the liposomes bearing CPZ-induced NPA, which have not been PKH26-stained (data not shown). A schematic representation of $\mathrm{SL}$, or L-NPA, is shown (Figures 1C-G).

\section{Mice Inoculated with Liposomes Bearing NPA Produce IgG Anti-NPA Antibodies}

Anti-NPA antibodies were readily detected in the sera of mice that received L-NPA intradermally; while these antibodies were not detected in mice that received only SL or SS. A proportion of the anti-NPA antibodies (13, 43, and $71 \%$ on days 10,20 , and 35 after first immunization, respectively) were of the IgG class (Figure 2A). In the mice that were injected intradermally in the inguinal region with L-NPA, anti-NPA antibodies were also detected since the 10th day after the first inoculation, and these antibodies increased progressively until the fourth month. Antihistone and anti-cardiolipin antibodies were detected a month later than the anti-NPA antibodies, and they also increased 

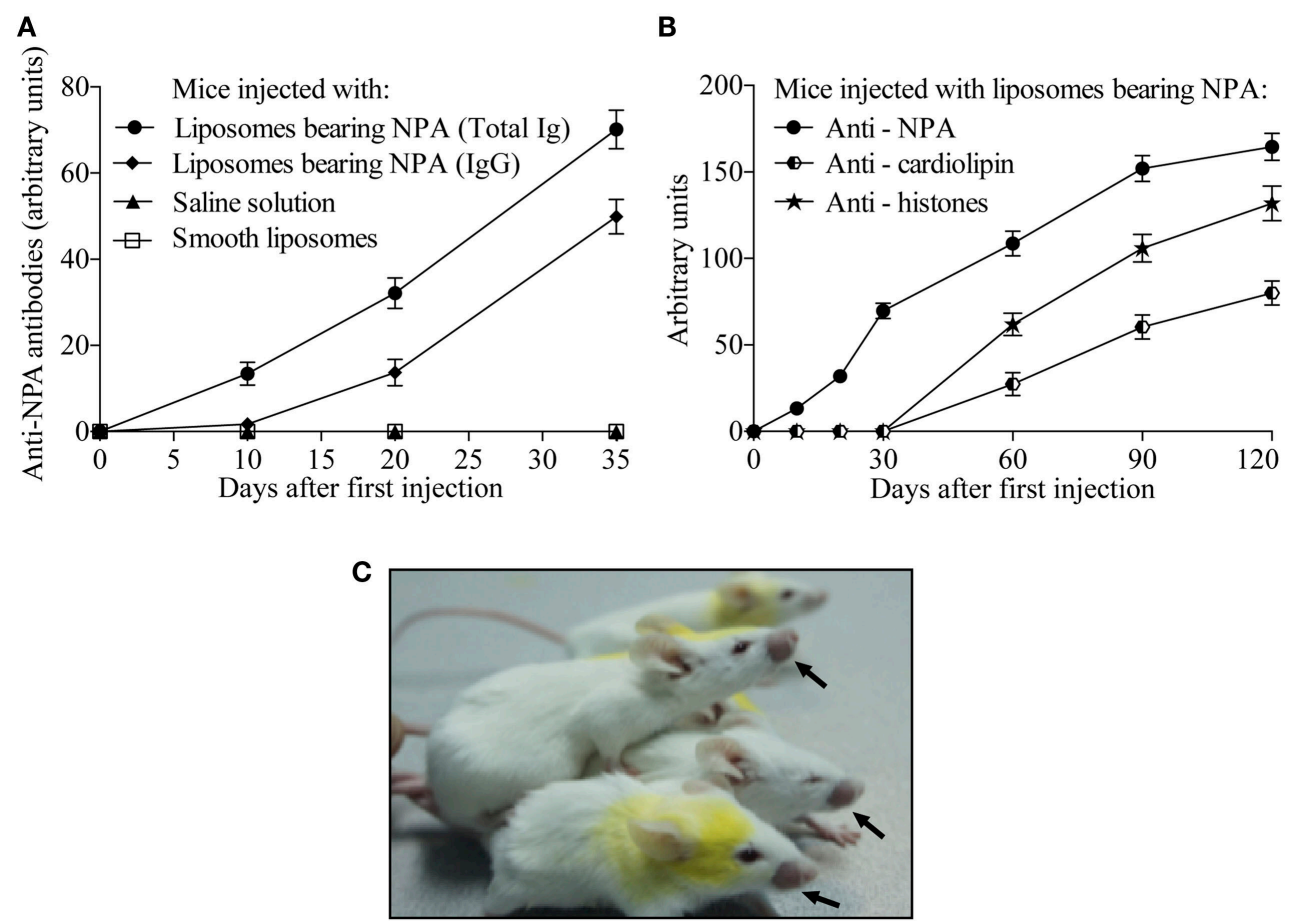

FIGURE 2 | Mice injected with liposomes bearing NPA produced IgG antibodies that specifically bind to NPA. Sera of mice injected either with saline solution, with smooth liposomes, or with liposomes bearing NPA were assayed by ELISA at the indicated days using as antigen the liposomes bearing NPA. Goat anti-mouse antibody to the IgG, IgM and IgA isotypes was used to assess total antibodies to NPA; whereas goat anti-mouse to lgG was used to assess only the IgG specific to NPA (A). Anti-NPA, anti-histones, and anti-cardiolipin antibodies were also measured by ELISA in the sera of mice injected intradermally with liposomes bearing NPA once a week for 4 months (B); 60\% of these mice developed facial lesions, as indicated by the arrows (C).

progressively until the fourth month (Figure 2B), which is consistent with previous reports $(5,9)$. These mice also developed facial lesions on the second month after the first injection of L-NPA (Figure 2C).

\section{Plasma Cells That Produce IgGs Specific to NPA Are Found in Mice with the Lupus- Like Disease}

To investigate the in vivo cellular mechanisms that lead to the production of IgG anti-NPA antibodies in this mouse model of lupus, we used flow cytometry. Cell suspensions were labeled with antibodies and with L-NPA stained with the red-fluorescent lipophilic dye $\mathrm{PKH} 26$, in order to identify cell populations specific for the inducing NPA antigen. PKH26-stained liposomes were tested as antigens in an ELISA, and no significant differences in the anti-NPA antibody titers were found, compared to nonstained L-NPA (data not shown). Specific plasma cells for NPA $\left(\mathrm{Gr}^{-}, \mathrm{CD} 19^{-}, \mathrm{CD} 138^{+}, \mathrm{NPA}^{+}\right)$were identified by flow cytometry (Figures 3A-D) in the draining lymph nodes, the spleen and the bone marrow of mice that received L-NPA; these NPA-specific plasma cells were not observed in mice that received either SL or SS (Figures 3E,F). The percentage of $\mathrm{IgG}^{+} \mathrm{NPA}$-specific plasma cells increased progressively, from $0.78,1.5$, and $1.63 \%$ on day 10 to $2.67,7.04$, and $7.27 \%$ on day 35 for the draining lymph nodes, the spleen and bone marrow, respectively (Figures 3G-I).
Concomitantly, the percentage of IgG ${ }^{-}$NPA-specific plasma cells decreased progressively from 0.75 and $7.2 \%$ on day 20 to 0.41 and $5.15 \%$ on day 35 for the draining lymph nodes and the spleen, respectively (Figures 3J,K); and from $6.48 \%$ on day 10 to $2.19 \%$ on day 35 for bone marrow (Figure 3L).

\section{NPA-Specific Germinal Center B Cells Are Found in Mice with the Lupus-Like Disease}

Germinal center B cells specific for NPA $\left(\mathrm{IgD}^{-}, \mathrm{CD}^{+} 9^{+}, \mathrm{PNA}^{+}\right.$, $\mathrm{NPA}^{+}$) were identified by flow cytometry (Figures 4A-D) in the draining lymph nodes and the spleen of mice that received L-NPA; these germinal center B cells were not found in mice that received only SL or SS (Figures $4 \mathrm{E}, \mathrm{F}$ ). The percentage of NPAspecific germinal center B cells increased progressively from 4.37 and $6.15 \%$ on day 10 to 16.37 and $19.87 \%$ on day 35 for the draining lymph nodes and the spleen, respectively (Figures 4G,H).

\section{Few NPA-Specific Extrafollicular B Cells Are Found in Mice with the Lupus-Like Disease}

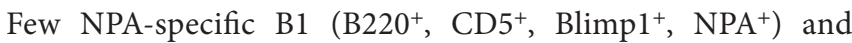

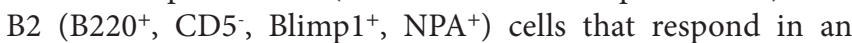
extrafollicular manner were identified by flow cytometry (Figures 5A-F) in the spleen of mice that received L-NPA; 


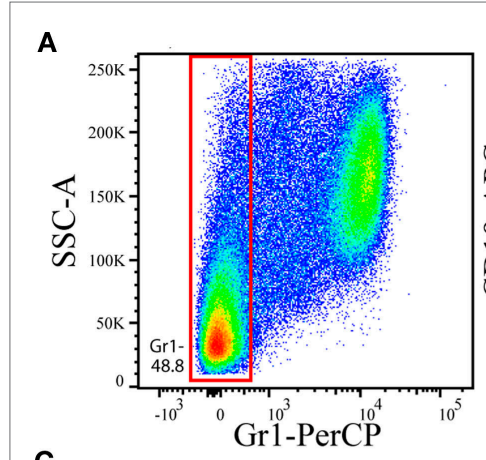

C
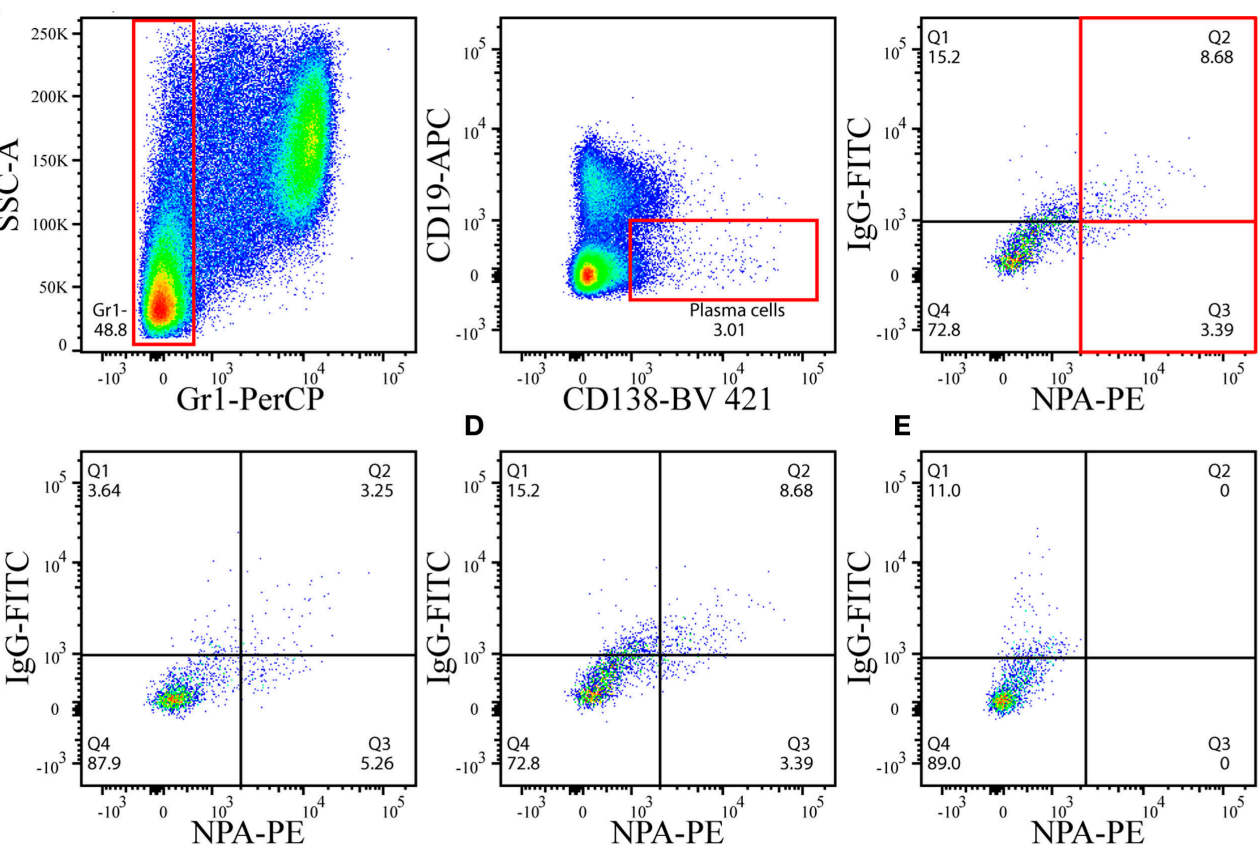

Spleen

G Draining lymph node

H I

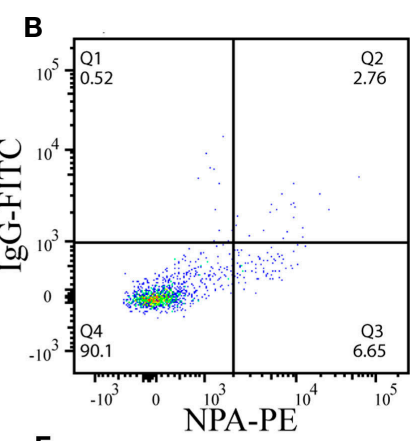

F

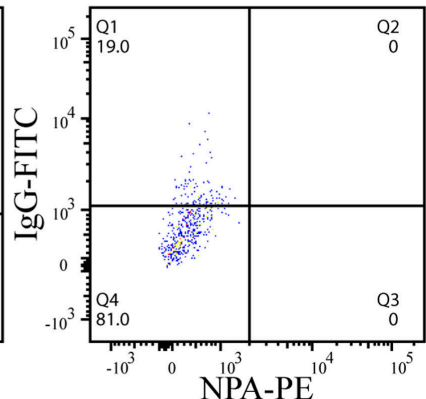

Bone marrow
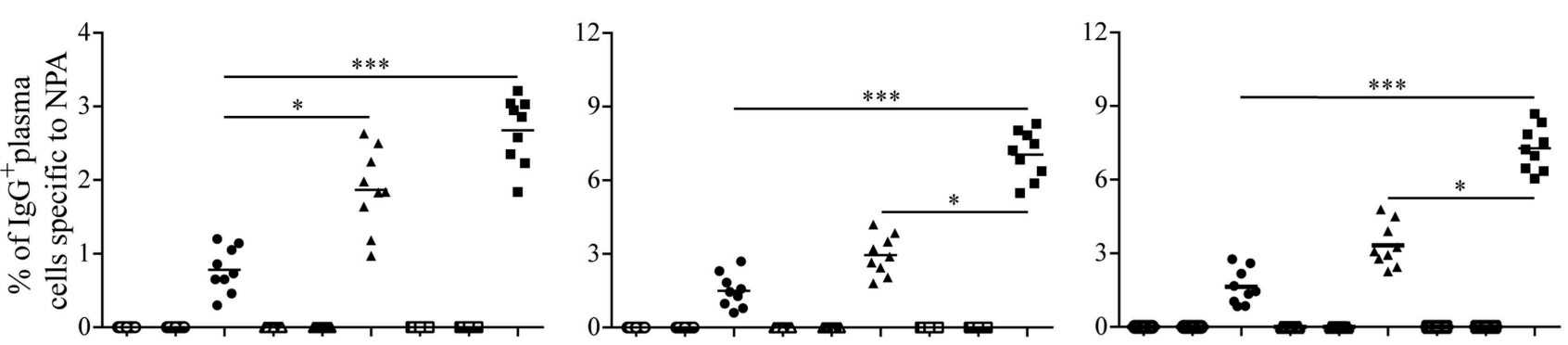

K

$\mathbf{L}$
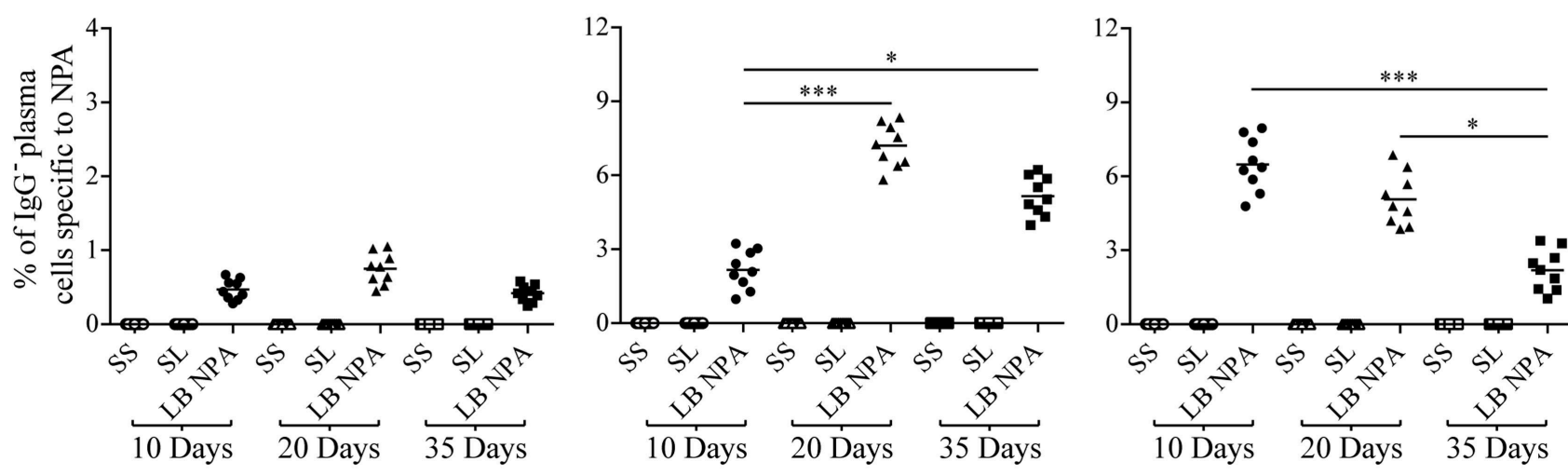

SS: Saline solution SL: Smooth liposomes LB NPA: Liposomes bearing NPA

FIGURE 3 | NPA-specific plasma cells from mice inoculated with liposomes bearing NPA. To identify NPA-specific plasma cells, cell suspensions from the draining lymph nodes, spleen, and bone marrow were co-labeled with antibodies to surface Gr1, CD19, and CD138 and intracellularly for IgG and with PKH26stained liposomes bearing NPA (NPA-PE), and were then analyzed by flow cytometry. Gating strategy to identify plasma cells specific to NPA (Gr1-', CD19-, CD138+, $\mathrm{NPA}^{+}$) (A). Region analysis shows the percentage of NPA-specific lgG+ and lgG- plasma cells on days 10 (B) 20 (C), and 35 (D) in the bone marrow of mice that had been inoculated with NPA-liposomes. Percentage of NPA-specific $\mathrm{IgG}^{+}$and IgG- plasma cells on day 35 in the spleens of mice inoculated with saline solution (E) or with smooth liposomes (F). Percentage of $\lg G^{+}$or $\lg G^{-}$plasma cells specific to NPA in the draining lymph nodes $(\mathbf{G}, \mathbf{J})$, spleen $(\mathbf{H}, \mathbf{K})$, and bone marrow $(\mathbf{I}, \mathbf{L})$ Kruskal-Wallis test with Dunn's post-test were used for statistical analysis; significance was set at $P<0.05$. Asterisks represent statistically significant differences between the indicated groups ( $\left.{ }^{\star} P<0.05,{ }^{\star \star \star} P<0.001\right)$. Each symbol represents pooled cells from two mice. SS, saline solution; SL, smooth liposomes; LB NPA, liposomes bearing NPA. 


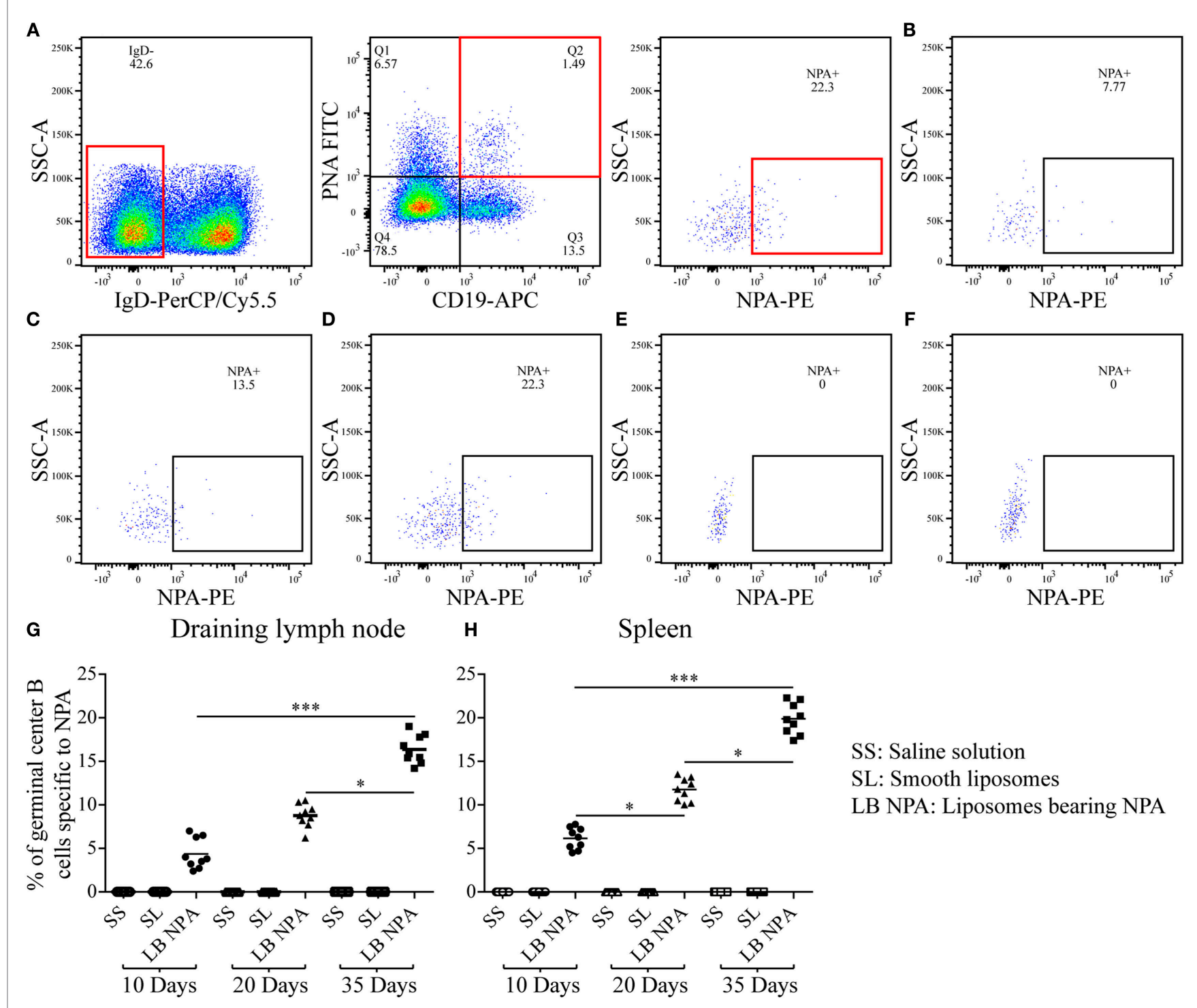

FIGURE 4 | Germinal center B cells specific to NPA from mice inoculated with liposomes bearing NPA. In order to identify NPA-specific germinal center B cells, cell suspensions from the draining lymph nodes and spleens were co-labeled with red-fluorescent PKH26-stained liposomes bearing NPA (NPA-PE), with antibodies to surface IgD and CD19 and with fluorescent PNA and analyzed by flow cytometry. Gating strategy to identify NPA-specific germinal center B cells (lgD-, $\mathrm{CD}^{+}{ }^{+}, \mathrm{PNA}^{+}, \mathrm{NPA}^{+}$) (A). Region analysis shows the percentage of NPA-specific germinal center B cells on days 10 (B), 20 (C), and 35 (D) in the spleens of mice that had been inoculated with NPA-liposomes. Percentage of NPA-specific germinal center B cells on day 35 in the spleens of mice inoculated with saline solution (E) or with smooth liposomes (F). Percentages of germinal center B cells specific to NPA in the draining lymph nodes (G) and spleen (H). Kruskal-Wallis test with Dunn's post-test were used for statistical analysis; significance was set at $P<0.05$. Asterisks represent statistically significant differences between the indicated groups ( $\left.{ }^{\star} P<0.05,{ }^{* \star \star} P<0.001\right)$. Each symbol represents pooled cells from two mice. SS, saline solution; SL, smooth liposomes; LB NPA, liposomes bearing NPA.

however only extrafollicular B2 cells specific to NPA were identified in the draining lymph nodes. These extrafollicular reaction $\mathrm{B}$ cells were not observed in mice that received only SL or SS (Figures 5G,H). The percentage of extrafollicular reaction $\mathrm{B} 1$ cells specific for NPA decreased progressively from $0.72 \%$ on day 10 to $0.0 \%$ on day 35 in the spleen (Figure $5 \mathrm{~J}$ ); while these cells were not detected in the draining lymph nodes of any of the groups examined (Figure 5I). The percentage of extrafollicular reaction B2 cells specific for NPA decreased progressively from 0.35 and $1.69 \%$ on day 10 to 0.0 and $0.19 \%$ on day 35 for the draining lymph nodes and the spleen, respectively (Figures 5K,L).

\section{NPAs Are Found in the Germinal Centers of Mice with the Lupus-Like Disease Induced by NPA-Immunizations}

Using the NPA-specific monoclonal antibody H308, NPAs were identified by immunofluorescence in the germinal centers of the draining lymph nodes 35 days after mice received L-NPA. 
A

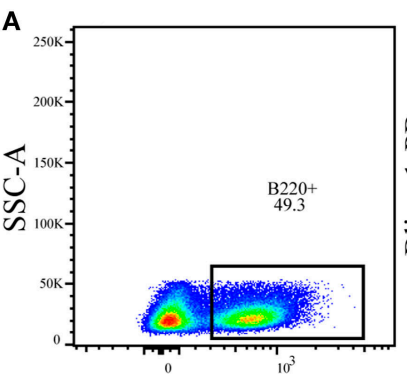

B220-FITC

E

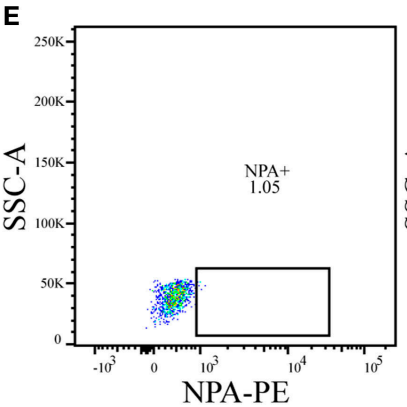

Draining lymph node

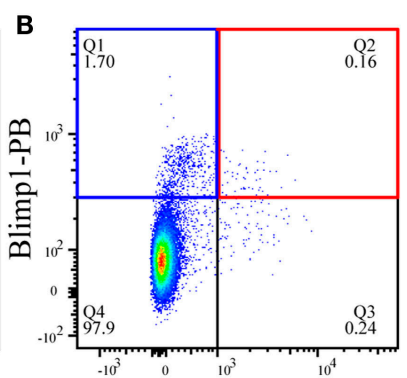

CD5-AF647

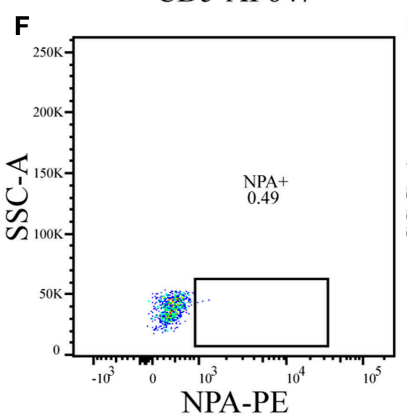

NPA-PE
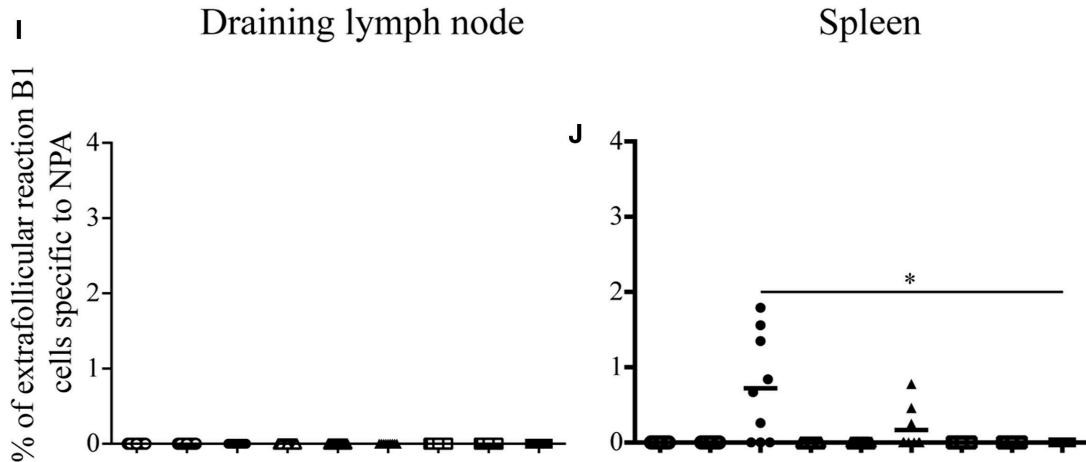

L
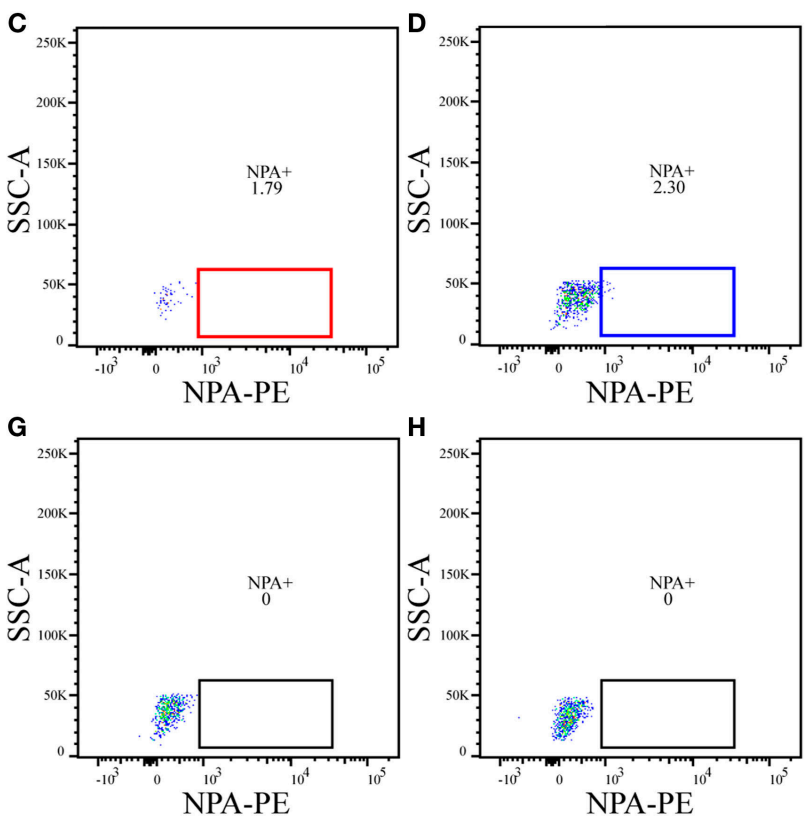

Spleen

SS: Saline solution

SL: Smooth liposomes

LB NPA: Liposomes bearing NPA
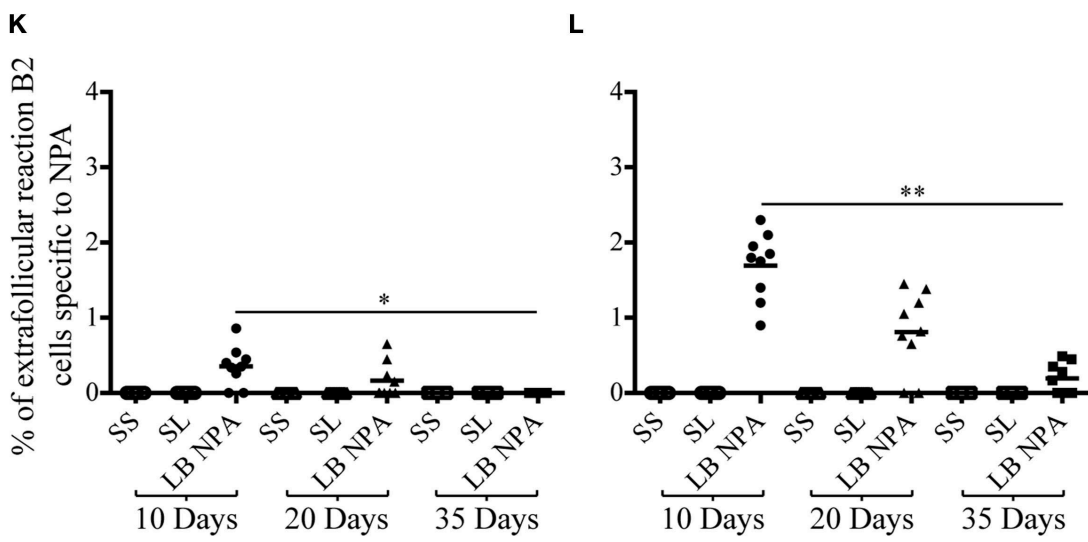

FIGURE 5 | Few extrafollicular reaction B cells specific to NPA were found in mice inoculated with liposomes bearing NPA. To identify NPA-specific extrafollicular reaction B cells, cell suspensions from the draining lymph nodes and spleen were concomitantly labeled with red-fluorescent PKH26-stained liposomes bearing NPA (NPA-PE), with antibodies to surface B220 and CD5 and to intracellular Blimp1, and analyzed by flow cytometry on the indicated days. Gating strategy to

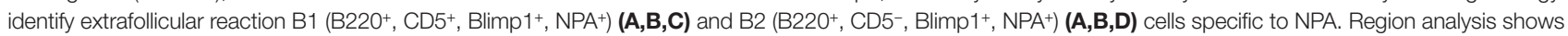
the percentage of NPA-specific extrafollicular reaction B2 cells on days 10 (D), 20 (E), and 35 (F) in the spleens of mice that had been inoculated with NPA-liposomes. Percentage of NPA-specific extrafollicular reaction B2 cells on day 35 in the spleens of mice inoculated with saline solution (G) or with smooth liposomes (H). Percentages of extrafollicular reaction B1 and B2 cells specific to NPA in the draining lymph node (I,K) and spleen (J,L), respectively. Kruskal-Wallis test with Dunn's post-test were used for statistical analysis; significance was set at $P<0.05$. Asterisks represent statistically significant differences between the indicated groups $\left({ }^{\star} P<0.05,{ }^{\star \star} P<0.01\right)$. Each symbol represents pooled cells from two mice. SS, saline solution; SL, smooth liposomes; LB NPA, liposomes bearing NPA. 
B220 delineates the B cell follicles (Figures 6A,B) and an IgDnegative area inside $\mathrm{B}$ cell follicles indicates the germinal centers (Figures 6C,D). These IgD-negative areas are positive for PNA (Figures 6E,F).

\section{The Affinity of the Anti-NPA IgG Antibodies Progressively Increases over Time}

To determine if affinity maturation, a hallmark of the antibodies produced via germinal center reactions, occurs during the course of the NPA-immunizations, we performed antigen-specific ELISAs for the anti-NPA IgG antibodies, both in the absence and in the presence of urea 7M. This is a well-established assay (20-22) used to test antibody affinities. Lower antibody affinities correlate with increased antibody decoupling from antigen under the astringent effects of urea. Conversely, higher antibody affinities lead to an increased proportion of antibodies that resist the effects of urea and remain bound to antigen. Using this assay, we obtained at each time point the percentage of urea-resistant

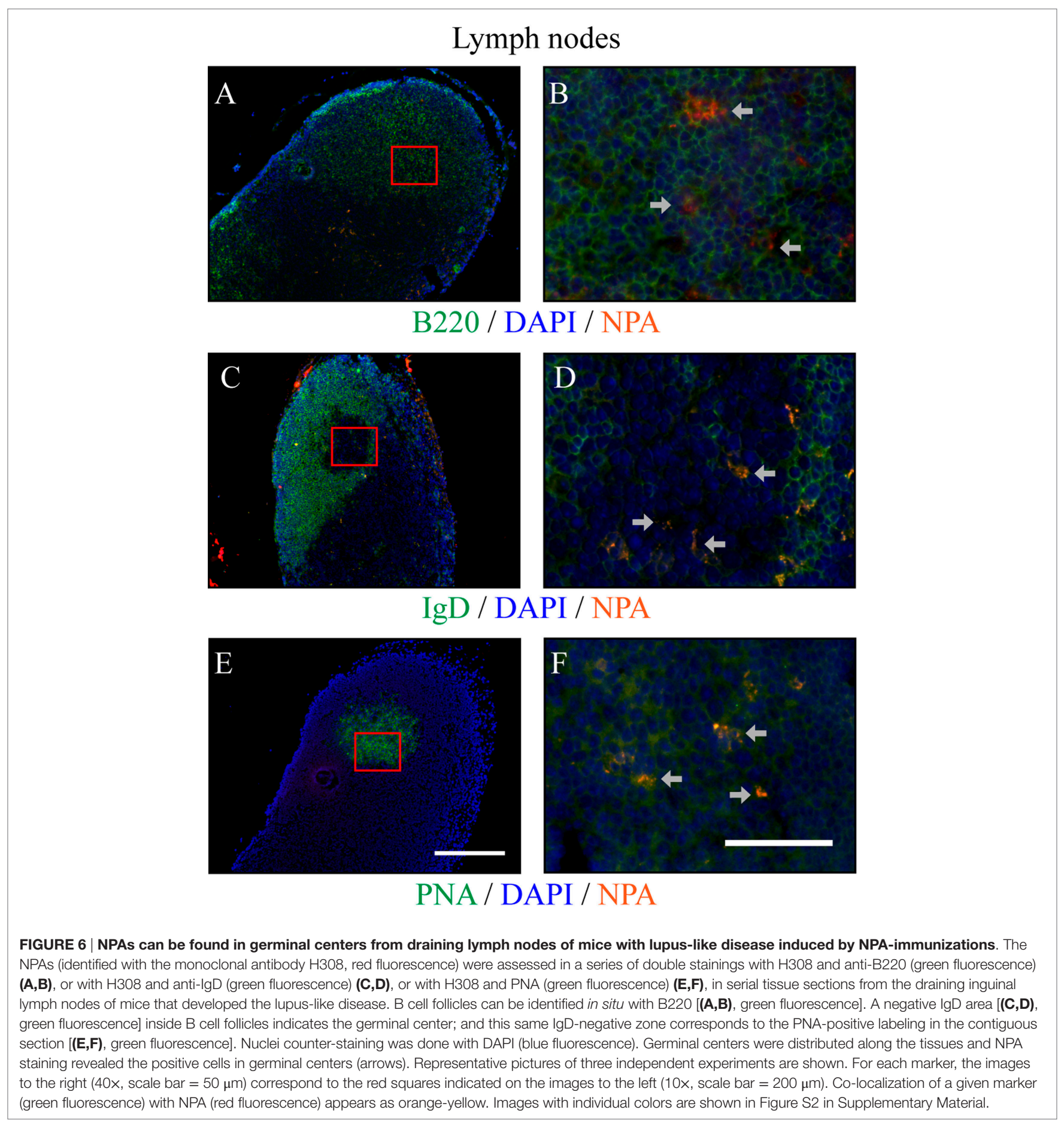


(high affinity) anti-NPA IgG antibodies, in relation to the total anti-NPA IgG antibodies. As illustrated in Figure 7, the proportion of urea-resistant antibodies was much lower at early time points (10 and 20 days post-NPA-injection) than at later time points $(35,60,90$, and 120 days post-NPA injection), which indicates that affinity has increased with time. In fact, at days 35, 60, 90, and 120 post-immunization, most anti-NPA IgG antibodies showed high affinities, revealing the maturation of affinity.

\section{DISCUSSION}

Compared to proteins, lipids are deemed rather poorly immunogenic molecules (3). However, anti-lipid antibodies have been found in patients with infectious diseases, such as leprosy and tuberculosis $(1,10)$, and in patients with autoimmune diseases such as SLE (4); these antibodies are not only low-affinity IgM, but also high-affinity class-switched IgG antibodies. The cellular mechanisms that lead to the production of these IgM and IgG anti-lipid antibodies have not been elucidated and are poorly studied. To investigate these mechanisms, we assessed a mouse model of an autoimmune disease resembling human lupus, which develops in response to the administration of NPA (9). NPA are transient phospholipid molecular arrangements, different from the bilayer formed by lipids from cell membranes (8). These phospholipid associations are observed by electron microscopy

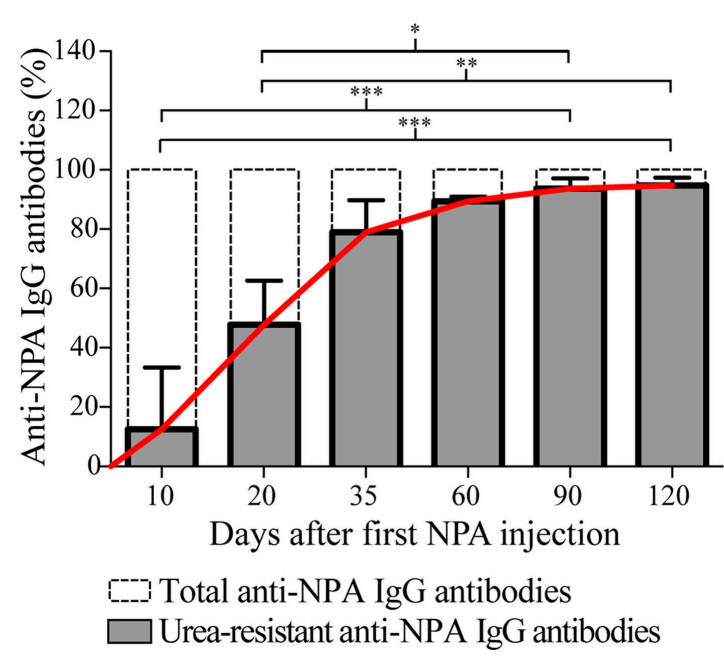

FIGURE 7 | The affinity of the anti-NPA IgG antibodies increases with time after immunization. Sera of mice injected at different time points with liposomes bearing NPA were assayed by ELISA on the indicated days, using liposomes bearing NPA as antigen, and goat anti-mouse IgG as secondary antibody. After incubation of the anti-NPA antibodies, urea 7M was added to each well for $10 \mathrm{~min}$ (secondary reagents were added after this). At each time point, the percentage of urea-resistant anti-NPA IgG antibodies (high affinity, shown in gray bars) and the total anti-NPA IgG antibodies (indicated with dotted bars) are represented. The progressive increase in the affinity of the IgG anti-NPA antibodies is indicated with the continuous red line; at late time points (day 35 onwards) most antibodies display high affinities. Percentages of urea-resistant antibodies at the indicated times were analyzed with Kruskal-Wallis test with Dunn's post-test; significance was set at $P<0.05$. Asterisks represent statistically significant differences between the indicated groups $\left({ }^{\star} P<0.05,{ }^{\star \star} P<0.01,{ }^{\star \star \star} P<0.001\right)$. as protuberances on the lipid matrix of liposomes (artificial membrane models). When lipids are associated in stable NPA, they become more immunogenic and induce the production of specific antibodies $(5,9)$. Here, we report for the first time that, in mice that developed an autoimmune disease resembling human lupus in response to the administration of NPA, B cells reacted mainly through the germinal centers to produce anti-NPA IgG antibodies.

In NPA, the polar heads of the phospholipids that form the outer region of this lipid structure are separated from each other, so they are exposed as new antigens; however, since NPA are transient structures, usually no immune response is elicited (5). Of note, when NPA are stabilized by drugs that induce lupus-like diseases in humans (23), such as CPZ, promazine, procainamide, and hydralazine, an immune response is generated with the production of anti-NPA antibodies. Interestingly, in mice, these same drugs trigger the development of an autoimmune disease similar to human lupus. We have already demonstrated, with hapten inhibition studies, that the epitope recognized by these antibodies is glycerolphosphorylcholine, the polar region of $\mathrm{PC}$, which is the most abundant phospholipid in animal cell membranes (9).

In previous studies, we found that a high percentage (60\%) of the anti-NPA antibodies that are found in the mice with the lupus-like disease are of the IgG class. To study the mechanisms that lead to the production of these anti-NPA switched IgG antibodies, we inoculated NPA to mice by intra-splenic injection (as we had done it before) $(5,9)$, but changed the administration of subsequent NPA boosting doses from intraperitoneal to intradermal injection in the inguinal region, so that we could monitor the (systemic) immune response in the spleen and in the draining (regional) lymph node. The mice that received NPA by the intradermal route also generated anti-NPA antibodies, and $45 \%$ of these antibodies were IgG. These mice produced anti-cardiolipin and anti-histone antibodies 1 month after the appearance of the anti-NPA antibodies, and $60 \%$ of the mice had malar rash. These results indicate that these mice had an autoimmune disease with very much the same characteristics to the disease that develops in response to the administration of NPA by the intraperitoneal route, as we previously reported $(5,9)$.

During the production of class-switched IgG antibodies against most protein antigens, $\mathrm{B}$ cells respond in vivo mainly via the germinal center or (to a lesser degree) the extrafollicular reaction, and subsequently differentiate into plasmablasts and plasma cells that produce IgG antibodies $(11,14,24)$. To identify the specific cells producing the anti-NPA antibodies, liposomes with or without NPA were stained with the lipophilic (red fluorescent) dye PKH26. This staining did not affect the structure of the NPA in the liposomes, because L-NPA and stained with PKH26 were equally recognized by anti-NPA mouse sera or even by a monoclonal anti-NPA antibody, while control liposomes without NPA but equally stained with $\mathrm{PKH} 26$ were not recognized by these anti-NPA antibodies. Therefore, L-NPA and stained with PKH26 were used to identify anti-NPA antibody-producing cells by flow cytometry. With this strategy, we found plasma cells ( $\mathrm{Gr}^{-}$, $\mathrm{CD}_{19}^{-}, \mathrm{CD}_{138^{+}}, \mathrm{NPA}^{+}$) that produce anti-NPA antibodies in the secondary lymphoid organs (draining lymph node and spleen) of mice with the lupus-like disease. We also found plasma cells in the 
bone marrow, which is the organ to which these cells can migrate after their differentiation in the secondary lymphoid organs (25). To avoid false-positive results, granulocytes $\left(\mathrm{Gr}^{+}\right)$, which can uptake most types of small particles and molecules, including antibodies, were excluded from the flow cytometry analysis.

The percentage of plasma cells that produce anti-NPA IgG antibodies increased gradually in the three organs analyzed (lymph nodes, spleen, and bone marrow), while the percentage of IgG-negative NPA-specific plasma cells decreased in these same organs at 10,20, and 35 days after the first administration of NPA. This plasma-cell response is similar to that described for protein antigens (26). A larger number of plasma cells specific to NPA was found in the spleen, compared to the draining lymph node, and this may be attributed to the populations of B cells (B1 cells and marginal zone B cells) that are present in the spleen, but not in the lymph nodes, and which could generate such plasma cells (25).

After identifying the specific plasma cells producing antiNPA IgG antibodies, we investigated the route by which B cells responded, and found that the reaction of anti-NPA B cells was mainly via the germinal centers. Germinal centers provide the microenvironmental requirements for the interactions between follicular T and B cells that lead to the generation of high-affinity IgG antibodies against protein antigens (12). IgG antibodies against several lipids (lathosterol, 7- $\alpha$-hydroxycholesterol, cardiolipin, and oxidized PC) have been found in SLE patients (27), and IgG antibodies against long-chain saturated fatty acids have been found in the sera of patients with type 2 diabetes (28). IgM and IgG anti-cholesterol antibodies have been detected even in healthy individuals, as well as in patients with atherosclerosis and viral infections (29-31). However, the cellular mechanisms that lead to the production of these anti-lipid antibodies are still poorly understood. The main cells providing help to B cells for the production of anti-lipid antibodies seem to be NKT cells rather than CD4 T cells. For instance, NKT cells, not conventional CD4 $\mathrm{T}$ cells, provide cognate help to $\mathrm{B}$ cells specific for 4 -hydroxy-3-nitrophenyl- $\alpha$-galactosyl-ceramide (NP- $\alpha \mathrm{GalCer}$ ), which produce anti-NP IgG antibodies (32). It has been shown that invariant-chain NKT cells (iNKT cells) can cooperate with $B$ cells and induce the rapid formation of germinal centers to glycolipid antigens (33). iNKT cells can recognize synthetic, selfand microbial glycolipids, as well as self-phospholipid antigens presented by CD1d (34); and in patients with SLE it has been shown that iNKT cells promote the production of IgG antibodies and auto-antibodies (35). In fact, iNKT cells can adopt a phenotype that corresponds to that of follicular T helper cells, with high expression of CXCR5, PD-1, and Bcl-6, and the secretion of IL-4, IFN- $\gamma$, IL-21, and BAFF. These iNKT cells can be found in germinal centers and they provide help to B cells in a CD40CD40L-dependent manner, which leads to the production of IgG antibodies $(33,36,37)$. It is, thus, conceivable that iNKT cells might be cooperating with B cells for the production of anti-NPA IgG antibodies (38), but this needs to be demonstrated.

The percentage of germinal center $\mathrm{B}$ cells $\left(\mathrm{IgD}^{-}, \mathrm{CD} 19^{+}\right.$, $\mathrm{PNA}^{+}, \mathrm{NPA}^{+}$) specific to NPA was higher in the lymph nodes and the spleen than the percentage of extrafollicular reaction $\mathrm{B} 2$ cells $\left(\mathrm{CD}^{-}, \mathrm{B} 220^{+}, \mathrm{Blimp1}^{+}, \mathrm{NPA}^{+}\right)$, especially on day 35 after the first immunization. We also found the antigen (NPA) inside the germinal centers of the draining lymph nodes of mice that developed the lupus-like disease. Extrafollicular reaction $\mathrm{B} 1$ cells $\left(\mathrm{CD}^{+}, \mathrm{B} 220^{+}, \mathrm{Blimp}^{+}, \mathrm{NPA}^{+}\right)$were not detected in the draining lymph node (where they are usually absent), and very few were detected in the spleen, where they decreased until they became undetectable by day 35 . In general, this pattern regarding the percentage of germinal center $\mathrm{B}$ cells and extrafollicular reaction $\mathrm{B} 1$ and B2 cells that reacted against NPA is similar to that described for protein antigens. Affinity maturation is a crucial process during antibody responses and occurs mainly during germinal center reactions; thus, the fact that we detected that the affinity of these anti-NPA IgG antibodies progressively augmented with time after immunization strongly supports the notion that these antibodies were produced via germinal centers.

The production of antibodies by plasma cells is a critical process to maintain human health as it provides immunity after the exposure to a pathogen and mediates the protective effects of most vaccines. While the $\mathrm{B}$ cell-differentiation process to generate plasma cells that produce antibodies to protein antigens has been extensively studied, reports regarding these events in the case of lipid antigens are scarce. However, these same anti-lipid antibodies-producing cells might be involved in clinically relevant diseases, such as autoimmunity and infection. It is crucial, therefore, to understand the mechanisms of B cell differentiation to plasma cell, particularly as it relates to the generation of classswitched IgG antibodies, not only in response to protein antigens but also to lipid antigens, which might be involved in clinically relevant autoimmune and infectious diseases.

\section{ETHICS STATEMENT}

The study was approved by the Comite de Bioetica de la Escuela Nacional de Ciencias Biologicas (CEI-ENCB-025/2014) and the Comité de Bioetica del CINVESTAV (CD-2013-01).

\section{AUTHOR CONTRIBUTIONS}

Conceived and designed the experiments: CW-B, IB, and LF-R. Performed the experiments and the acquisition of data: $\mathrm{CW}-\mathrm{B}$, AR-M, LD-M, LZ-N, JY-P, JC-A, and YM. Analyzed the data, interpretation, and discussion: CW-B, IW-B, CW, IB, and LF-R. Wrote and revised the paper: CW-B, IW-B, IB, and LF-R. Final approval of the version to be published: LF-R.

\section{ACKNOWLEDGMENTS}

This study was supported by grants from the Instituto Politécnico Nacional, Mexico (SIP20140969 to IB and SIP20144298 to CW), and from the National Council for Science and Technology (CONACYT) (221102 to LF-R). AR-M, LD-M, and JY-P are fellow holders from CONACYT Mexico. CW-B, IW-B, JC-A, CW, IB, and LF-R are members of the National System of Researchers, SNI-CONACYT. The personnel of Cinvestav animal facilities UPEAL, especially René Pánfilo-Morales, Ricardo GaxiolaCenteno and Rafael Leyva-Muñoz, are acknowledged with thanks. Authors also thank Dr. Nonantzin Beristain for helpful discussions on iNKT cells. 


\section{SUPPLEMENTARY MATERIAL}

The Supplementary Material for this article can be found online at http://journal.frontiersin.org/article/10.3389/fimmu.2016.00396

FIGURE S1 | Three groups (A, B, and C) of adult mice were divided into three subgroups of six mice each. One subgroup received saline solution (SS), the other smooth liposomes (SL), and the last one liposomes bearing NPA (L-NPA). On day 1, group A received complete Freund's adjuvant (CFA) (intraperitoneally, i.p.) and SS, SL, or L-NPA (intrasplenic, i.s.); on day 2, SS, SL, or L-NPA (intradermally, i.d.) and sacrificed on day 10. On day 16 , group B received the same as group A plus incomplete Freund's adjuvant (ICFA, i.p.)

\section{REFERENCES}

1. de los Angeles Garcia M, Borrero R, Marron R, Lanio ME, Canet L, Otero O, et al. Evaluation of specific humoral immune response and cross reactivity against Mycobacterium tuberculosis antigens induced in mice immunized with liposomes composed of total lipids extracted from Mycobacterium smegmatis. BMC Immunol (2013) 14(Suppl 1):S11. doi:10.1186/1471-2172-14-S1-S11

2. Careaga M, Hansen RL, Hertz-Piccotto I, Van de Water J, Ashwood P. Increased anti-phospholipid antibodies in autism spectrum disorders. Mediators Inflamm (2013) 2013:935608. doi:10.1155/2013/935608

3. Asherson RA. The Antiphospholipid Syndrome. Boca Raton; London: CRC Press (1996). 339 p.

4. Suurmond J, Diamond B. Autoantibodies in systemic autoimmune diseases: specificity and pathogenicity. J Clin Invest (2015) 125(6):2194-202. doi:10.1172/JCI78084

5. Baeza I, Leyva E, Campos B, Lara M, Ibanez M, Farfan N, et al. Antibodies to non-bilayer phospholipid arrangements induce a murine autoimmune disease resembling human lupus. Eur J Immunol (2004) 34(2):576-86. doi:10.1002/ eji. 200324177

6. Hafez IM, Cullis PR. Roles of lipid polymorphism in intracellular delivery. Adv Drug Deliv Rev (2001) 47(2-3):139-48. doi:10.1016/S0169-409X(01) 00103-X

7. Jouhet J. Importance of the hexagonal lipid phase in biological membrane organization. Front Plant Sci (2013) 4:494. doi:10.3389/fpls.2013.00494

8. Cullis PR, de Kruijff B, Hope MJ, Nayar R, Schmid SL. Phospholipids and membrane transport. Can J Biochem (1980) 58(10):1091-100. doi:10.1139/ o80-147

9. Wong-Baeza C, Hernandez-Pando R, Resendiz A, Tescucano A, Bustos I, Ibanez M, et al. Molecular organization of the non-bilayer phospholipid arrangements that induce an autoimmune disease resembling human lupus in mice. Mol Membr Biol (2012) 29(2):52-67. doi:10.3109/09687688. 2012.667577

10. Baeza I, Wong-Baeza C, Valerdi E, Serafin-Lopez J, Ibanez M, Estrada-Parra $S$, et al. Lepromatous leprosy patients produce antibodies that recognise non-bilayer lipid arrangements containing mycolic acids. Mem Inst Oswaldo Cruz (2012) 107(Suppl 1):95-103. doi:10.1590/S0074-027620120 00900016

11. MacLennan IC, Toellner KM, Cunningham AF, Serre K, Sze DM, Zuniga E, et al. Extrafollicular antibody responses. Immunol Rev (2003) 194:8-18. doi:10.1034/j.1600-065X.2003.00058.x

12. Basso K, Dalla-Favera R. Germinal centres and B cell lymphomagenesis. Nat Rev Immunol (2015) 15(3):172-84. doi:10.1038/nri3814

13. Marshall JL, Zhang Y, Pallan L, Hsu MC, Khan M, Cunningham AF, et al. Early $B$ blasts acquire a capacity for Ig class switch recombination that is lost as they become plasmablasts. Eur J Immunol (2011) 41(12):3506-12. doi:10.1002/ eji.201141762

14. MacLennan IC. Germinal centers. Annu Rev Immunol (1994) 12:117-39. doi:10.1146/annurev.iy.12.040194.001001

15. De Silva NS, Klein U. Dynamics of B cells in germinal centres. Nat Rev Immunol (2015) 15(3):137-48. doi:10.1038/nri3804

16. de Vinuesa CG, Cook MC, Ball J, Drew M, Sunners Y, Cascalho M, et al. Germinal centers without T cells. J Exp Med (2000) 191(3):485-94. doi:10.1084/jem.191.3.485 and SS, SL, or L-NPA (i.s.); on day 17, SS, SL, or L-NPA (i.d.) and sacrificed on day 20. Finally, group $C$ received the same as groups $A$ and $B$ plus $S S$, SL, or L-NPA (i.d.) on day 32 and sacrificed on day 35. Samples were taken before immunization and on the days of sacrifice.

FIGURE S2 | Individual and merged images of labeled tissue sections from draining lymph nodes. Individual images of the draining lymph nodes from mice with lupus-like disease induced by NPA-immunizations were taken with the Olympus BX51 microscope; green fluorescence for B220 (A), IgD (E), and PNA (I); blue fluorescence for nuclei counter-staining (DAPI) (B,F,J) and red fluorescence for NPAs (C,G,K). Merged images of B220/DAPI/PNA (D), IgD/ DAPI/NPA (H), and PNA/DAPI/NPA (L). Images were merged with Image-Pro PLUS software.

17. Chappell CP, Draves KE, Giltiay NV, Clark EA. Extrafollicular B cell activation by marginal zone dendritic cells drives $\mathrm{T}$ cell-dependent antibody responses. J Exp Med (2012) 209(10):1825-40. doi:10.1084/jem.20120774

18. Aguilar L, Ortega-Pierres G, Campos B, Fonseca R, Ibanez M, Wong C, et al. Phospholipid membranes form specific nonbilayer molecular arrangements that are antigenic. JBiol Chem (1999) 274(36):25193-6. doi:10.1074/ jbc.274.36.25193

19. National Research Council (U.S.). Guide for the Care and Use of Laboratory Animals (Committee for the Update of the Guide for the Care and Use of Laboratory Animals). Washington, D.C.: National Academies Press (2011).

20. Khurana S, Verma N, Yewdell JW, Hilbert AK, Castellino F, Lattanzi M, et al. MF59 adjuvant enhances diversity and affinity of antibody-mediated immune response to pandemic influenza vaccines. Sci Transl Med (2011) 3(85):85ra48. doi:10.1126/scitranslmed.3002336

21. Puschnik A, Lau L, Cromwell EA, Balmaseda A, Zompi S, Harris E. Correlation between dengue-specific neutralizing antibodies and serum avidity in primary and secondary dengue virus 3 natural infections in humans. PLoS Negl Trop Dis (2013) 7(6):e2274. doi:10.1371/journal.pntd.0002274

22. Westerlund A, Ankelo M, Simell S, Ilonen J, Knip M, Simell O, et al. Affinity maturation of immunoglobulin A anti-tissue transglutaminase autoantibodies during development of coeliac disease. Clin Exp Immunol (2007) 148(2):230 40. doi:10.1111/j.1365-2249.2007.03336.x

23. Dalle Vedove C, Simon JC, Girolomoni G. Drug-induced lupus erythematosus with emphasis on skin manifestations and the role of anti-TNFalpha agents. JDtsch Dermatol Ges (2012) 10(12):889-97. doi:10.1111/ j.1610-0387.2012.08000.x

24. Vinuesa CG, Linterman MA, Goodnow CC, Randall KL. T cells and follicular dendritic cells in germinal center B-cell formation and selection. Immunol Rev (2010) 237(1):72-89. doi:10.1111/j.1600-065X.2010.00937.x

25. Nutt SL, Hodgkin PD, Tarlinton DM, Corcoran LM. The generation of antibody-secreting plasma cells. Nat Rev Immunol (2015) 15(3):160-71. doi:10.1038/nri3795

26. Poskin A, Verite S, Comtet L, Van der Stede Y, Cay B, De Regge N. Persistence of the protective immunity and kinetics of the isotype specific antibody response against the viral nucleocapsid protein after experimental Schmallenberg virus infection of sheep. Vet Res (2015) 46(1):119. doi:10.1186/s13567-0150260-6

27. Jovanovic V, Abdul Aziz N, Lim YT, Ng Ai Poh A, Jin Hui Chan S, Ho Xin Pei E, et al. Lipid anti-lipid antibody responses correlate with disease activity in systemic lupus erythematosus. PLoS One (2013) 8(2):e55639. doi:10.1371/ journal.pone.0055639

28. Nicholas DA, Salto LM, Boston AM, Kim NS, Larios M, Beeson WL, et al. Identification of anti-long chain saturated fatty acid IgG antibodies in serum of patients with type 2 diabetes. Mediators Inflamm (2015) 2015:196297. doi:10.1155/2015/196297

29. Biro A, Horvath A, Varga L, Nemesanszky E, Csepregi A, David K, et al. Serum anti-cholesterol antibodies in chronic hepatitis-C patients during IFN-alpha-2b treatment. Immunobiology (2003) 207(3):161-8. doi:10.1078/0171-2985-00229

30. Horvath A, Fust G, Horvath I, Vallus G, Duba J, Harcos P, et al. Anti-cholesterol antibodies (ACHA) in patients with different atherosclerotic vascular diseases and healthy individuals. Characterization of human ACHA. Atherosclerosis (2001) 156(1):185-92. doi:10.1016/S0021-9150(00)00630-4 
31. Veres A, Fust G, Smieja M, McQueen M, Horvath A, Yi Q, et al. Relationship of anti-60 kDa heat shock protein and anti-cholesterol antibodies to cardiovascular events. Circulation (2002) 106(22):2775-80. doi:10.1161/01. CIR.0000038890.39298.8D

32. Leadbetter EA, Brigl M, Illarionov P, Cohen N, Luteran MC, Pillai S, et al. NK T cells provide lipid antigen-specific cognate help for B cells. Proc Natl Acad Sci U S A (2008) 105(24):8339-44. doi:10.1073/pnas.0801375105

33. King IL, Fortier A, Tighe M, Dibble J, Watts GF, Veerapen N, et al. Invariant natural killer $\mathrm{T}$ cells direct $\mathrm{B}$ cell responses to cognate lipid antigen in an IL-21-dependent manner. Nat Immunol (2012) 13(1):44-50. doi:10.1038/ ni. 2172

34. Vinuesa CG, Chang PP. Innate B cell helpers reveal novel types of antibody responses. Nat Immunol (2013) 14(2):119-26. doi:10.1038/ni.2511

35. Shen L, Zhang H, Caimol M, Benike CJ, Chakravarty EF, Strober S, et al. Invariant natural killer $\mathrm{T}$ cells in lupus patients promote $\mathrm{IgG}$ and $\operatorname{IgG}$ autoantibody production. Eur J Immunol (2015) 45(2):612-23. doi:10.1002/ eji.201444760

36. Chang PP, Barral P, Fitch J, Pratama A, Ma CS, Kallies A, et al. Identification of Bcl-6-dependent follicular helper NKT cells that provide cognate help for B cell responses. Nat Immunol (2012) 13(1):35-43. doi:10.1038/ni.2166

37. Tonti E, Fedeli M, Napolitano A, Iannacone M, von Andrian UH, Guidotti LG, et al. Follicular helper NKT cells induce limited B cell responses and germinal center formation in the absence of CD4(+) T cell help. JImmunol (2012) 188(7):3217-22. doi:10.4049/jimmunol.1103501

38. Wong-Baeza C, Tescucano A, Astudillo H, Resendiz A, Landa C, Espana L, et al. Nonbilayer phospholipid arrangements are toll-like receptor-2/6 and TLR-4 agonists and trigger inflammation in a mouse model resembling human lupus. J Immunol Res (2015) 2015:369462. doi:10.1155/2015/369462

Conflict of Interest Statement: The authors declare that the research was conducted in the absence of any commercial or financial relationships that could be construed as a potential conflict of interest. CW and IB are listed as authors in the following patents: (1) US Patent 6,777,193, Methods for diagnostic and/or treatment of anti-phospholipid antibodies-related diseases and devices, and (2) US Patent 7,867,723, Methods for anti-phospholipid syndrome.

Copyright (C) 2016 Wong-Baeza, Reséndiz-Mora, Donis-Maturano, Wong-Baeza, Zárate-Neira, Yam-Puc, Calderón-Amador, Medina, Wong, Baeza and Flores-Romo. This is an open-access article distributed under the terms of the Creative Commons Attribution License (CC BY). The use, distribution or reproduction in other forums is permitted, provided the original author(s) or licensor are credited and that the original publication in this journal is cited, in accordance with accepted academic practice. No use, distribution or reproduction is permitted which does not comply with these terms. 